\title{
A Critical New Pathway Towards Change in Abusive Relationships: The Theory of Transition Framework
}

\author{
Yael Shy $\cdot$ Linda G. Mills
}

Published online: 28 May 2010

(c) The Author(s) 2010. This article is published with open access at Springerlink.com

\begin{abstract}
This article explores the use of "Transition Framework" as a conceptual framework for individual and social change. William Bridges introduced Transition Framework in the $1970 \mathrm{~s}$ as a three-pronged model explaining how people respond to change in their lives. This article argues that such an approach has the potential to help clients recognize and grieve the loss of their old identities, become comfortable with new ways of communicating, understand their cycles of relapse and make positive changes. The relevance of this model to transformative change in domestic violence treatment is explored.
\end{abstract}

Keywords Domestic violence - Change theory ·

Transition framework - Offender treatment - Batterers . Intervention

During the recent presidential election, slogans such as, "Change we can believe in," and "Change we need," were broadly welcomed by Americans as promises sure to usher in a new era of growth and prosperity. But when change happens in our lives-how do we react? What encourages us to develop and evolve? What keeps us stuck in old

Y. Shy

Center on Violence and Recovery, New York University,

New York, NY, USA

L. G. Mills

Silver School of Social Work,

New York University, New York, NY, USA

L. G. Mills ( $\square)$

New York University, Elmer Bobst Library, 70 Washington

Square South, 1242, New York, NY 10012, USA

e-mail: linda.mills@nyu.edu patterns of resistance? These questions have particular significance for people involved in abusive relationships. Can a violent person change his/her behavior? If so, how?

William Bridges, a humanist and internationally known author, developed his theory about the dynamics of transition in the 1970s in order to help individuals and organizations deal effectively with change. Since that time, his books, seminars, and lectures on the "Transition Framework" have taught hundreds of businesses and thousands of individuals essential skills in navigating through the process of change.

The Transition Framework (TF) is built on a distinction between change and transition (Bridges 2003). "Change" is the circumstantial situation in which one finds oneself and "transition" is the psychological processing that occurs as a result of that change. Bridges points out that while we are often conscious that a change is occurring, we are less aware of our emotional response to it (Bridges 2003). Carefully attending to that emotional response increases the likelihood that positive changes will have a lasting effect and that difficult changes will give way to the possibility of healing and growth.

In 2004, New York University's (NYU) Center on Violence and Recovery partnered with a judge and several community leaders in Nogales Arizona to create a nonprofit-Construyendo Circulos de Paz/Constructing Circles of Peace (CCP). This organization uses an innovative restorative justice circle approach to treat intimate partner violence. Restorative justice is a process that can be applied after a wrongdoing or crime has occurred and involves all stakeholders in collectively identifying and addressing "harms, needs, and obligations in order to heal and put things as right as possible" (Zehr 2002, p. 37). NYU's Center on Violence and Recovery ("NYU") advances knowledge on the causes of intimate and 
community violence and develops innovative solutions that promote healing. Restorative justice is one important approach the Center uses to address violence.

In addition to restorative justice, CCP's founders decided to adopt TF as a central feature of its treatment approach. They received a grant from the Andrus Family Fund (2000)—a small foundation dedicated to utilizing philanthropy to affect positive change. The grant was for the implementation of the TF for families affected by domestic violence within the restorative justice model; TF had been used previously in the fields of business (Bridges 2003), nursing (Mason et al. 1998), and foster care (Andrus Family Fund 2000). In order to facilitate use of the Framework, the Andrus Family Fund provided a TF Coach to CCP and all Circle facilitators were taught how to identify the transitions in their own lives and the lives of their clients. CCP facilitators were also given useful tools and techniques to guide their clients through their transitions.

Circle facilitators introduce TF to clients at the first Circle, and continue to reference it throughout the course of treatment. Facilitators lay out the three different stages of TF (explained in detail, below) and encourage clients to come up with examples of where they are in their transition process. Facilitators then note their clients' progress and outcomes in the use of TF in weekly client progress notes.

The results of the collaboration between Andrus Family Fund, CCP, and NYU have been positive and instructive: TF has offered clients who were attempting a unique form of domestic violence treatment a valuable language with which to validate personal experiences. It also offered tools they could use to weather the difficult and challenging process of change and to embrace new and non violent behaviors. CCP is engaging in a rigorous, year-long evaluation to determine whether the TF systematically contributes to successful attitudinal and behavioral change. The results are expected in late 2010 .

This article explores the theory behind the use of TF in domestic violence treatment settings and suggests how the theory might be useful to practitioners as they begin to experiment with new methods of treatment with clients. Case examples, extracted from CCP's weekly progress notes by program staff, are used for illustrative purposes for the overall goal of offering TF as a new theory and possible tool to practitioners. The authors suggest that TF can help facilitate healing and growth for clients perpetrating intimate partner abuse and can therefore be a valuable approach for agencies seeking new ways to incorporate a transition model into their treatment philosophy. In-depth study regarding its overall and sustained effectiveness is still necessary; hence the purpose of the year-long evaluation. Other practitioners who adopt TF on an experimental basis are also encouraged to evaluate its effectiveness.

\section{Transition Framework}

Transition Framework is built on the theory that change is situational and transitions are psychological. Changes are outside events that happen to a person (the loss of a job, getting arrested, or marrying). Transitions, on the other hand, are internal to the person (how one feels when one loses a job, is arrested, or married).

Transitions are composed of a three-staged process through which one comes to terms with the changes in one's life (Bridges 2003). William Bridges, who developed the theory, calls these three stages "endings," the "neutral zone," and "new beginnings" (Bridges 2003). "Endings" describes the letting go process, how individuals relinquish old ways of approaching situations as well as old identities that inform those ways of being in the world. Bridges asserts that identifying and acknowledging what is involved in an ending - whether positive or negative-and grieving for what is lost, is crucial for working through those feelings and arriving in a position to accept the change (Bridges 2003).

Once people become ready to let go of old patterns, they enter "the neutral zone." In this phase, they are not yet comfortable with a new way of doing things, and find themselves suspended in an "in-between place." The "neutral zone," therefore, often feels chaotic to those experiencing it. A person in the neutral zone asks, "What's next?" or, "What should I do now?" It is a place where psychological "realignment and repatterning" take place, and therefore, while it is unsettling, it is also the place where a lot of creativity occurs.

The final stage of one's transition through a change is "new beginnings." People experiencing this phase develop a new identity and begin to incorporate their behavior or identity changes into a new way of seeing the world. They are no longer held back by the pent up and unaddressed feelings that so often prevent the change process from occurring.

In order to better understand the theory in practice, consider this example: Steve has a violent altercation with his wife, Lisa, and following his arrest, Lisa announces that she is leaving him. Steve's arrest, sentence, and Lisa leaving him are the changes. Steve's response to these changes begins the transition. He reels from the news. He experiences shock, denial, anger, and despair. He is in "endings" - the difficult period of grieving for his life as he knew it. Once Steve absorbs the fact that his marriage has really ended, he feels lost and unmoored. His identity (Steve, "the husband"), and his sense of security (my wife 
will never leave me because she loves me), has been upended. He doesn't know who he is anymore. This begins his journey through the "neutral zone." Gradually, Steve starts to realize that his anger and problems with women are deeply rooted, and lead back to old wounds he suffered as a child. In treatment, he starts to face the fact that his drug addictions exacerbate these problems, hurting those around him. He always knew these were deep problems but could not figure out how to solve them and was too afraid to attempt to change. Losing his wife-and the identity he built around her-allows Steve to open himself up to the possibility of healing and transformation. From an emotional standpoint, he is able to face the demons of his past and from a behavioral standpoint, he is able to learn other communication strategies and new ways of handling his emotions. This period of recognizing the creative possibilities of the change are also part of the neutral zone. As Steve moves through treatment, he begins to see himself as a stronger individual, able to better express love and to understand his anger and pain. He has reached a "new beginning."

Bridges is clear that these three transition phases rarely happen in distinct and perfectly defined zones or periods, marked by beginnings and endings. On the contrary, they often occur in overlapping and concurrent contexts. The full transition, however, cannot be considered complete until there is closure on all three phases (Bridges 2003).

\section{Construyendo Circulos de Paz/Constructing Circles of Peace}

Construyendo Circulos de Paz (CCP), founded in 2004, is the nation's first court-referred domestic violence treatment and prevention program to use a restorative justice circle approach to reduce violent behavior in families (Mills 2005). Participants in the program are court-referred following a conviction of a domestic violence crime. The program consists of 26-52 weeks of conferences, or "Circles," that bring partners who have been abusive together with their families (including the victims if they choose to participate), as well as a trained professional facilitator and community volunteers, in order to encourage dialogue and goal-oriented change. The extended family (siblings, parents, cousins, etc.) participates in the treatment when available, and their presence helps those in the Circle understand the intergenerational transmission of the violence-a common phenomenon (Mills 2008a, b). The presence of the family also serves to hold abusive partners accountable to those whom they look to for guidance and respect. A Safety Monitor (someone close to the family) is officially appointed at the first Circle and performs frequent check-ins at the couple's home, intervening or seeking help if tensions begin to rise. Circles are enhanced through mental health, job placement, and drug and alcohol treatment services, when necessary or helpful (Mills 2005).

\section{TF Case Examples Drawn From CCP Program Notes}

The case examples in this article are drawn from the weekly case notes and supplemental narrative evaluations of 65 court-referred clients (called "applicants"). This group includes all the clients treated at CCP during the 2006-2007 calendar year. The data was gathered in connection with a yearly program report (with all names and identifying details redacted) and the findings forwarded to the foundation. All clients at CCP were introduced to TF during this time period, and had the opportunity to apply it to their lives. The client files were systematically reviewed for any and all references to TF.

Six different facilitators were trained in $\mathrm{TF}$ and kept weekly case notes. These case notes were relatively unstructured, providing a blank space for the facilitator to note any details noteworthy to the client's progress or status. Narrative evaluations, by contrast, were focused exclusively on the client's progress in relation to the Transition Framework and were filled out by the facilitator on the first, thirteenth and twenty-sixth session of treatment. In the narrative evaluations, facilitators were asked to comment on the content of the circle discussion as it related to TF, the facilitator's own role in the circle, and the facilitator's impressions and thoughts about the circle process.

Although not a formal study of the program, these case examples are of immediate benefit to the development of a theoretical model for those clients and/or organizations who are seeking an understanding of the change process. The progress notes yielded the following key insights into the usefulness of TF for Circle treatment:

- TF helps clinicians understand that initial resistance to treatment on the part of clients is usually a signal that the client is experiencing ambivalence about change, and needs assistance in grieving the loss of old behaviors and identities. Calling this stage "endings," helps clients locate themselves in a larger framework.

- TF helps clients become more comfortable with new ways of communicating and behaving through "compensation for losses" (a concept developed by William Bridges), and the use of visualization and planning exercises.

- TF helps hold clients accountable to their transition goals by encouraging them to involve friends and family in their treatment as sources of support through the loneliness of the change process. 
- $\mathrm{TF}$ is particularly useful when clients relapse into destructive behavior, as it contextualizes such behavior as a natural aspect of the process of growth called the "neutral zone."

- TF helps clients maintain positive behaviors by continually re-focusing them on their internal responses to change. This awareness helps them become successful in the "new beginnings" stage.

\section{Transition Framework in a Domestic Violence Setting: Building a Theoretical Framework}

\section{Endings}

In the early stages of most batterers' treatment programs, clients are frequently resistant to the idea of intervention and defensive about changing their behavior. Many who have perpetrated violence "deny their abuse, minimize the severity of its effects, claim their partners provoked or deserved the abuse, or report that external forces caused the abuse" (Murphy and Baxter 1997, p. 607). In one study, approximately one-third of men attending batterer intervention programs agreed with statements such as, "I am not the problem one" and "I don't have a problem that I need to change" (Scott and King 2007, p. 8, p. 401).

The common protocol for working with defensive and resistant clients in traditional batterer intervention programs is direct confrontation and re-education (Murphy and Baxter 1997). As Murphy and Baxter (1997) have noted, advocates of the traditional "gender reeducation" approach assert that "any failure to confront, head on, instances of victim blaming, denial, or minimization amounts to collusion by the therapist with the abusive behavior" (p. 608). In most programs, the resistant client is assumed to be refusing to change or is fundamentally opposed to change. The treatment provider's role is to break down the defenses of the client through continual confrontation, thereby "jolting" the batterer into behavioral change (Murphy and Baxter 1997).

Pence et al. (1993), in their seminal batterer treatment handbook, Education Groups for Men Who Batter: The Duluth Model, give an example of a typical confrontation with a batterers' group. The facilitator asks one batterer, "John, is it scary to live with you?" John responds, "Sometimes." The facilitator asks why, and John responds that his father was terrifying to live with, and that John "took after" him. After asking the same question of the rest of the group, the facilitator says, "What is this list? Fathers, Vietnam, the army, mothers, booze, drugs, unfaithful wives? These could all look like pretty good reasons to be violent, but how about all the men who've had those same experiences and didn't become violent-what happened with them?" (Pence et al. 1993, p. 74).

Research suggests that these confrontational techniques may not be as effective as once believed. Indeed, there is some research to suggest that confrontation of this sort can cause serious risks of deterioration for clients with low self-concept, low self-esteem, borderline personality disorders, and histories of childhood abuse (Marshall and Serran 2004, p. 310). In marital and family therapy in particular, some of the factors that have been found to lead to client deterioration are when the therapist:

(a) has poor relationship skills; (b) gives little guidance in early sessions; (c) uses frontal confrontation of defenses and other highly affective material, (d) labels unconscious motivations early on rather than reflecting feelings, gathering data, stimulating interaction, and giving support, and (e) does not moderate feedback to participants with low ego strength. (Murphy and Baxter 1997, p. 611)

Although Murphy and Baxter (1997) are quick to note that these conclusions have not been extensively tested, they also highlight the fact that many batterers' treatment manuals, including the most popular Duluth model, advocate for the use of these specific techniques in treatment, despite the fact that they might be ineffective and/or dangerous.

Mills (2008a, b) has argued that confrontational approaches miss the opportunity to understand and work supportively with violent adults who so often have a childhood history of violence and shame that have scarred them. Mills writes that these violent adults often use violence to "cover up" those histories (Mills 2008a, b). While a childhood history does not excuse an adult's abusive behavior, it should still be relevant to how a therapeutic intervention is designed and implemented.

It is widely recognized in psychotherapy that resistant clients are those who are ambivalent about change (Scott and King 2007), as opposed to what is often misunderstood as the desire to dominate and control. Scott and King (2007) have noted that clients exhibit resistance to therapy when they have expressed a desire to change, have identified a strategy or therapist that might help them make that change, express distress about not changing, and yet, continue to alternate between approaching and avoiding tasks necessary for change. "Presumably," they write, "this alternation occurs due to conflicts (both conscious and unconscious) between clients' wishes and fears" (Scott and King 2007, p. 406).

Why are clients ambivalent about change? For many people convicted of domestic violence crimes, their arrest and subsequent treatment threatens to destabilize their identities, their worldviews, their methods of communication, and their 
relationships with others. Arrest and treatment are often catalytic events that cause clients to see that the ways they have coped with their angry feelings have spun out of control. They often want to change this part of themselves for fear of losing their partner, their family, and their jobs, and yet, they are terrified of who they will become without the crutch of violence. If our goal is to help people in this predicament to change so that they no longer rely on their abusive behavior, we need to understand their struggles in relinquishing the pattern of violence in their lives.

In William Bridges' book, "Managing Transitions," (2003) the author encourages those in the "endings" phase to "expect and accept" the signs of grieving in relation to the change they are facing. These signs of grieving include anger, bargaining, anxiety, sadness, disorientation, and depression (Bridges 2003). When people are supported through this grieving process and encouraged to mourn their past and face their fears about losing their old ways of relating and communicating, they are able to move on to create new possibilities for themselves, both in their behavior and in their identity or sense of self.

In addition to expecting and accepting the signs of grieving, Bridges also introduces several other techniques for this process. One is called "compensating for losses," or offering the person who is losing something in the transition a way to "balance what's been taken away" (Bridges 2003, p. 31) by developing a vision of what is possible for him or her through continued treatment. Indeed, Daniels and Murphy (1997) argue that when encouraging someone to move from contemplating change into actually making change, "special attention must be paid to increasing the client's perception of the benefits of change, rather than simply the negative aspects of the problem" (p. 134).

Finally, Bridges also suggests that when an ending is occurring, it is best to treat the past with respect, marking that ending in a ceremonial way. Pranis et al. (2003) write extensively about the importance of ceremonies in the recovery process. The flexible nature of the Circle process allows for culturally-specific ceremonies that help move people through these endings in treatment groups "provid[ing] a safe and uncontaminated space where ... inner wounds can be opened and cleaned, so that they can begin to heal" (pp. 240-241).

\section{The Neutral Zone}

The neutral zone-the time between letting go of the old ways and feeling comfortable with the new reality-is often the most difficult and uncomfortable time for people experiencing change. Bridges (2003) warns that it is a period when anxiety is raised and motivation falls. Many people, when faced with the discomfort of this difficult part of the transition, will try and bypass or escape the neutral zone, and become disappointed when they cannot do so (Bridges 2003). This disappointment frequently leads them to relapse into old, destructive behavior.

Prochaska et al. (1992), who have extensively researched the processes by which people make changes in their lives, characterize relapse as "the rule, rather than the exception" (p. 1104) when an individual is trying to change. They describe change as a spiral, rather than a linear progression, where the person progresses and relapses in an overall forward-moving direction.

There are several techniques for moving clients through the neutral zone. Perhaps the most important is normalizing and validating the client's chaotic and disorienting experience of this period. "One of the most difficult aspects of the neutral zone," Bridges (2003) writes, "is that most people don't understand it ... people need to recognize that it is natural to feel somewhat frightened and confused at such a time" (p. 43). Similarly, if they relapse during this period (and many will), clients need to understand that it is not an undoing of their progress, but a step along the way towards change in a difficult period (Daniels and Murphy 1997).

Aside from validation and explanation, clients can be assisted in moving through the neutral zone by including supporters and loved ones in the process of transition. The neutral zone is a lonely time. When people are experiencing transition and the possibility of changing their behavior and identity, they may feel increasingly isolated from the people and world they once occupied (Bridges 2003). When their communication strategies change and they no longer rely on violence, so too are their companions likely to change. "Few people thrive in isolation," Pranis et al. (2003) describe, "yet that's exactly how we feel in the middle of trauma or upheaval. Experiencing ourselves as isolated makes a hard situation worse, because it cuts us off from the resources we have, both in ourselves and in families and communities, to turn things around" (p. 212). Similarly, Prochaska et al. (1992) teach clinicians and doctors to encourage their clients and patients to identify and lean-on their social support networks in the period between contemplating change and taking steps in that direction. The social network then encourages the individual on his path toward change- - both as victims and witnesses of the negative behavior-and as a community that supports him as he reforms his behavior and identity.

The final characteristic of the neutral zone (and arguably its most important) is the innovation and creative problemsolving that has room to grow when all the ways of being, including attitudes and behavior, are unraveling. "It is during the gap between the old and the new," Bridges (2003) writes, that one's "immune system is weak enough to let a seedbed for novelty form" (p. 50). Daniels and 
Murphy (1997) state that clinicians working with clients in the "action" stage, a stage similar to the Neutral Zone, need to offer a menu of possible change strategies to the client and "provide training, encouragement, and reinforcement" when clients find strategies that work for them (p. 138).

\section{New Beginnings}

The new beginnings stage is the culmination of the transition process, but it carries its own challenges as well. Bridges (2003) writes that people are often ambivalent about beginnings - they want them to happen but are afraid of them as well. Beginnings often reactivate old anxieties from when the behavior ended, because they "ratify" that ending with finality; clients often feel that there is no "going back," whether or not they are ready for such finality (Bridges 2003). According to Prochaska et al. (1992), clients best maintain their changes when they not only are prepared for the conditions likely to lead them to relapse, but also when they feel comfortable with alternative coping mechanisms that do not require them to resort to "self-defeating defenses and pathological responses" (Prochaska et al. 1992, p. 59). The authors note that these alternative techniques are most effective when they are based on the client's conviction that the changes have given the client a new sense of self, one in which both she, and at least one significant other, highly value.

The final part of leading people through a new beginning is celebrating the success. This involves marking the new beginning, similar to the marking of an ending. This ritual enables people to take stock of their progress and to appreciate the road traveled (Bridges 2003).

\section{Transition Framework at Construyendo Circulos de Paz/Constructing Circles of Peace}

The TF model can best be understood and appreciated through implementation efforts. Facilitators at $\mathrm{CCP}$ implemented TF in 2006, and were instructed to introduce their clients to the Framework and record the results in their progress notes after each session. The facilitators were also encouraged to note their own thoughts and feelings about each particular client's progress or setbacks. These progress notes were the basis from which the themes were culled and presented in this article.

\section{Endings}

At CCP, clients vary in how they present in the early stages of the Circle treatment. Some degree of "resistance," however, is almost always present. Evaluations (prior to the first Circle) and early progress notes frequently include statements describing the applicant as "not happy about coming to Circles" (Liza ${ }^{1}$, Circle 26) (speaking about how she felt at the beginning) and "depressed about her situation and see[ing] no change in sight" (Liza). Others are described as "feeling stuck ... doesn't know what to do regarding his situation" (Chris). Chris, a client in his thirteenth week of treatment, continued to complain about the "outsiders" in the Circle (community member, facilitator, support people), and claimed that the Circle was not helping him. When the facilitator asked if Chris wanted to request a transfer to a different treatment program, however, Chris relented and "talked about how much he enjoy[ed] having a place to rest in this Circle" (Chris). The facilitator noted, "He sounds confused." This confusion about giving up his "old ways" reflects the deep ambivalence clients often feel towards letting go, even while looking for new ways to act.

The Circle Facilitator works with clients like Chris by employing the TF to help him understand his confusion and ambivalence about treatment, and by empathetically validating and working through his fears related to endings. For example, facilitators frequently try to "compensate for losses" by having clients envision and describe the change they want in their relationships. In one Circle, a facilitator did this by asking a mutually-abusive couple in the Circle what they would wish for if they had "magic fairy dust." They answered that they wished they could listen to each other more, have better communication, more patience with each other, and more self-esteem (Jorge and Myra). This exercise allowed the couple to envision the possibility of living a life free of abuse, even if this ideal was not yet in reach.

Amelia, who had been abused by her husband, specifically mentions endings in the first Circle in the presence of her husband: "She says she has ended many things and one is the way she used to love [her husband, who was recently admitted into rehab] as an addict." Amelia expressed a desire for help and support from the Circle in learning to understand her husband as his new, sober self (Julian).

\section{The Neutral Zone}

Many clients at CCP express relief when learning about the neutral zone, and many identify strongly with the description of its characteristics. Julian, mentioned above, was arrested for striking his wife, Amelia. He described his relationship with Amelia post-arrest as being in the "neutral zone."

$\overline{1}$ All names have been changed. 
[Julian] said that he and his wife want a new beginning but are not sure where to start... He explained that to him, the neutral zone was like a scary river full of debris hitting him every which way...He wanted to share his pain about being in this neutral zone and feeling that he and his wife were in that place together but not helping each other" (Julian).

The facilitator validated the fear that dominated this transition period for Julian and the creative possibilities that might open up for him and Amelia.

As mentioned earlier, Bridges (2003) identifies the neutral zone as a lonely period and emphasizes the importance of involving the family and friends of the circle participant on the path towards change. Inviting the support networks of the abuser and the abused (if he or she chooses to participate) to take part in treatment has been a hallmark of CCP since its inception. CCP was founded on the well-established fact that abuse in families is nearly always intergenerational and dynamic (Mills 2008a, b). The involvement of family/ friends in the treatment not only helps the entire family understand generational legacies of pain and abuse, but also supports clients during the frightening neutral zone and empowers them to heal and move forward.

An example of the power of such involvement in helping a client cope in the neutral zone can be seen in the Circle of one CCP client, Nick. Nick was a young man and a drug user who hit his mother one evening and was arrested. One day at Circle, Nick expressed anger at himself and his pattern of progress and relapse in the Circle where his parents were also present. The facilitator used the occasion to talk about relapse as a normal part of recovery, and the non-linear nature of the neutral zone:

Nick was reluctant to accept that one can relapse and still stay on course towards new beginnings. He stated that he had relapsed because he had no self-control. [Nick's] father told Nick that he [Nick's father] has been fighting his addictions for years and that things changed for him when he finally decided to end the old behavior. He said he understood where [Nick] was standing because he'd been there for years. [Nick's] mom cried and told Nick that no matter what, she would always help him...Nick got up and hugged his mom. Everyone began to cry (Nick).

Through Circle treatment with his parents, Nick grew to understand his own addiction to drugs and violence in the context of his father's addictions. His mother's support helped him to see his relapse as part of the healing process, and bolstered his efforts to move forward.

To harness the neutral zone's creative, problem-solving potential, CCP facilitators work with participants to develop a "Social Compact." The Social Compact commits to writing the client's goals for change and restoration throughout the twenty-six weeks of treatment. As the Circle progresses and discussions deepen, the Compact is regularly revised to include new goals and directions (Mills 2005). The goals can sometimes be incident-related (controlling anger, building healthy communication skills), economic (getting a better job, opening a new business), and/or they can be relationship-focused (spending more time with family, showing appreciation to a partner). One client said that his number one goal at the end of the 26 weeks was to take responsibility for his actions: "He says he used to think that anything bad that happened to him was because of bad luck and after attending circles he changed his mind," the facilitator notes. "He now believes he is "the builder of his destiny" (Pedro). Depending on the needs of the individual and the family, the facilitator attempts to water the seeds for change in the neutral zone, so that the new beginnings can take root.

\section{New Beginnings}

New beginnings can trigger old anxieties about risk and failure (Bridges 2003). A good example is CCP client Marcos, who, in his twenty-sixth session, "feels like he has made new changes, and they are already having an effect, but he is still ... nervous about his ability to remember what he learned as he moves forward" (Marcos). Facilitators explore these triggers and fears with their clients and try to validate them.

Additionally, calling attention to the client's new sense of self is a critical part of solidifying "new beginnings," and the Circle provides a community of people who do that reinforcing work together. The result is an internalization of the change, and a stronger ability to maintain it. One client, featured in a documentary about CCP, explained: "My daughter-I'm very close to her and I wasn't close to her before. She tends to give me a lot of love ... we are a family again, and that makes me feel proud of myself" (O’Neill 2008).

Celebration is also a critical component of the Circle model. For the vast majority of clients and families at CCP, there is much to celebrate as one enters the New Beginnings phase at the end of treatment. One client wrote in a letter to the program, "I am committed to continue applying what I learned on my [CCP] program [to] my every day life ... with support and aid from my family, [who] has been there for me without judging or criticizing my old ways of doing things" (Letter to Program, Archie). Another client noted, "One little change leads to another and very soon there are so many changes you lose count. But overall the feeling inside transitions is a good one and it brings peace to my heart and home" (Pedro). Such 
statements reveal the profound change that becomes a part of people's lives when they arrive at new beginnings, and the value of being explicit about pointing out transitions on the road to change.

\section{Summary and Future Research}

The implementation of TF at CCP has enabled the organization to successfully treat very difficult cases of domestic violence by recognizing that the change that is expected from clients who have been abusive involves "a process." Staying attuned to Bridges' framework and the accompanying three transitional zones has freed the facilitators to watch for signs of growth and setback, understanding that both are likely to occur when someone is experiencing change. The framework has helped clinicians, clients, and family members in the $\mathrm{CCP}$ program to be engaged in the change process in a deliberate and selfconscious way, tracking little behaviors and markers that eventually add up to meaningful change. This stands in contrast to most treatment programs that expect change without staying attuned to the process, and are then disappointed when it doesn't arrive. TF therefore provides a lens through which clinicians can see the emotions and behaviors associated with change and a methodology to help ease their clients through the process.

The accounts of clients working through the phases of transition and changing their behaviors and attitudes reveal practical and transformational properties of the TF. They also serve as an example for other organizations looking to adopt this philosophy into their clinical settings. A larger and more systematic study comparing clients who use the TF to those who do not is key to determining how effective $\mathrm{TF}$ is in easing a process of transformation. Information gleaned from the theory and progress notes indicate that such research has the potential to help clients, families, and agencies to realize deep change.

Open Access This article is distributed under the terms of the Creative Commons Attribution Noncommercial License which permits any noncommercial use, distribution, and reproduction in any medium, provided the original author(s) and source are credited.

\section{References}

Andrus Family Fund. (2000). Retrieved August 2008, from the Andrus Family Fund Web site http://www.affund.org/home.html
Bridges, W. (2003). Managing transitions: Making the most of change (2nd ed.). New York, NY: Da Capo P.

Daniels, J. W., \& Murphy, C. M. (1997). Stages and processes of change in batterer's treatment. Cognitive and Behavioral Practice, 4, 123-145.

Marshall, W. L., \& Serran, G. A. (2004). The role of the therapist in offender treatment. Psychology, Crime \& Law, 10(3), 309-320.

Mason, D. J., \& Leavitt, J. K. (Eds.). (1998). Policy and politics in nursing and health care (3rd ed.). Pennsylvania: W.B. Saunders.

Mills, L. G. (2005). Peacemaking circles/Construyendo Circulos de $P a z$ (CCP) (pp. 1-52). New York, NY: New York Center on Violence and Recovery.

Mills, L. G. (2008a). Shame and intimate abuse: The critical missing link between cause and cure. Children and Youth Services Review, 30, 631-638.

Mills, L. G. (2008b). Violent partners: A breakthrough plan for ending the cycle of abuse. New York: Basic Books.

Murphy, C. M., \& Baxter, V. A. (1997). Motivating batterers to change in the treatment context. Journal of Interpersonal Violence, 12(4), 607-619.

O'Neill, P. (Producer). (2008). Circles of peace: A new program addressing domestic violence. [Documentary Picture]. Oakland, CA: Working Group.

Pence, E., Paymar, M., \& Ritmeester, T. (1993). Education groups for men who batter: The Duluth model. Boston, MA: Springer.

Pranis, K., Stuart, B., \& Wedge, M. (2003). Peacemaking circles: From crime to community. St. Paul, MN: Living Justice Press.

Prochaska, J. O., DiClemente, C. C., \& Norcross, J. C. (1992). In search of how people change. American Psychologist, 47, $1102-1114$.

Scott, K. L., \& King, C. B. (2007). Resistance, reluctance and readiness in perpetrators of abuse against women and children. Trauma, Violence \& Abuse, 4(8), 401-417.

Zehr, H. (2002). The little book of restorative justice (pp. 1-76). New York: Good Books.

\section{Author Biographies}

Yael Shy is the Director of Development and Education at the New York University Center on Violence and Recovery and the Founding Director of the Spirituality Project at NYU. She received a J.D. from Northeastern University School of Law and a B.A. in Sociology and Gender Studies from New York University.

Linda G. Mills is New York University Professor of Social Work, Public Policy, and Law, as well as Senior Vice Provost for Undergraduate Education and University Life. Mills is also the Executive Director of the NYU Center on Violence and Recovery. 